CLINICAL ETHICS

\title{
Medical learning curves and the Kantian ideal
}

\author{
P Le Morvan, B Stock
}

See end of article for

J Med Ethics 2005;31:513-518. doi: 10.1136/jme.2004.009316

authors' affiliations

.....................

Correspondence to:

Pierre Le Morvan,

Department of Philosophy

and Religion, The College

of New Jersey, Ewing,

New Jersey 08628-0718,

USA; lemorvan@tcnj.edu

Received 8 May 2004

In revised form

30 October 2004

Accepted for publication

5 November 2004

\begin{abstract}
A hitherto unexamined problem for the "Kantian ideal" that one should always treat patients as ends in themselves, and never only as a means to other ends, is explored in this paper. The problem consists of a prima facie conflict between this Kantian ideal and the reality of medical practice. This conflict arises because, at least presently, medical practitioners can only acquire certain skills and abilities by practising on live, human patients, and given the inevitability and ubiquity of learning curves, this learning requires some patients to be treated only as a means to this end. A number of ways of attempting to establish the compatibility of the Kantian Ideal with the reality of medical practice are considered. Each attempt is found to be unsuccessful. Accordingly, until a way is found to reconcile them, we conclude that the Kantian ideal is inconsistent with the reality of medical practice.
\end{abstract}

$\mathrm{T}$ wo quotations from a surgeon in residence highlight central themes of this paper: "Surgeons, as a group, adhere to a curious egalitarianism. They believe in practice, not talent." "To fail to adopt new techniques would mean denying patients meaningful medical advances. Yet the perils of the learning curve are inescapable-no less in practice than in residency" (Gawande, ${ }^{1}$ p 26).

\section{INTRODUCTION}

Immanuel Kant offered the well known maxim: "Act so that you use humanity, as much in your own person as in the person of every other, always at the same time as end and never merely as means". ${ }^{2}$ Upholding this maxim in one's conduct entails that one should always treat each person as intrinsically valuable in his or her own right, and conversely that one should never use a person merely as a means or instrument toward attaining other goals. This principle-a plausible ethical ideal-seems particularly relevant to the field of medicine. Doctors and other health professionals are commonly regarded as having a special duty to look out for their patients' welfare.

In this paper, we explore a hitherto unexamined conflict between this Kantian ideal and the reality of medical practice. We will not focus on such clear ethical lapses as doctors or health care organisations exploiting patients for financial gain. Rather, we will discuss what seems to be a systematic and unavoidable source of conflict, even if the medical practitioners involved are well intentioned. This conflict arises from the fact that medical expertise must be learned. In brief, we will argue that developing and acquiring medical expertise requires practising on patients, with one's performance improving along a learning curve. Thus, patients treated at the beginning of the learning curve are exposed to higher risk, with later patients benefiting from this exposure. Using patients this way is, at least prima facie, a violation of Kant's principle.

To clarify, although we will mention some ethically questionable practices, our goal is not to find fault with medical learners or the institutions that train them. Rather, we want to explore the attainability of the Kantian ideal, given the demands of medical learning. Although our examples of such learning stem primarily from American and British sources, we believe that they exemplify an important truth about the human medical condition more generally, given the reality of medical learning curves in any extant society.

\section{LEARNING CURVES}

As Aristotle pointed out long ago, "medical men do not seem to be made by a study of textbooks". ${ }^{3}$ That is not to say that reading textbooks, or attending classes, is unimportant. But such activities do not suffice for attaining full expertise. One must acquire skills as well as factual knowledge-physical abilities and the ability to make correct judgments-and acquiring skills requires practice. "Book learning" is not enough.

The structure of medical education reflects this fact. One typically progresses from coursework, to observing and assisting experienced doctors and to supervised residency, before attaining full professional status.

Though advances in simulation and virtual reality technology may eventually obviate practising on live human patients, at least at this juncture in the history of medicine, "practice" necessarily includes practising on such patients. To be sure, even in Aristotle's time, novice healers could practise on animals, and today animal models are supplemented by preserved cadavers and synthetic models. Thus, one can acquire some skills prior to working on live humans. These alternatives do, however, have limitations. Some procedures-for example, inserting a central line, discussed in more detail below-involve locating specific features of the human anatomy and watching for biological responses that are not present in preserved cadavers or synthetic bodies. There is at present no substitute for a live, or very recently dead, human body.

How much practice is necessary for optimal performance? Naturally, that depends on the procedure and the practitioner. But the rate of improvement can be expressed graphically through a learning curve. T P Wright coined the term "learning curve" to describe the rate of increase in the productivity of airplane manufacturing workers. ${ }^{4}$ When workers repeat the same procedure, they typically become more efficient; repetition enables them to perform the procedure using less time and/or effort. Wright predicted that each time the production quantity is doubled, the labour hours needed to complete each unit will decrease by a 
constant percentage- the higher the percentage, the "steeper" the learning curve. ${ }^{4}$

Wright's specific predictions probably best apply only to quite monotonous activities, such as assembly line work. The general concept of a learning curve has, however, a much broader scope. Learning curves occur in any process where performance improves as a function of practice-for example, playing the guitar, teaching, or performing surgical procedures. In these examples, however, one is normally more interested in the improved quality of the results, rather than the decreased time and effort that Wright emphasised.

\section{THE TIP OF THE ICEBERG}

Two kinds of cases in which medical skills are developed through practice on patients have recently come under scrutiny. While striking, they represent only the tip of the iceberg. By comparing these cases, we can illustrate some important points about medical learning curves as they occur more generally.

\section{[A] Practising procedures on the newly dead}

Iserson offers the case of an elderly man, found collapsed on the street, who is brought to the emergency department, and promptly dies. ${ }^{5}$ No family members are present. The residents want to practise intubation and central lines on the man, procedures that cannot be effectively simulated on animals, plastic models, or preserved cadavers. Is it permissible for them to do this? In 2001, the Council on Ethical and Judicial Affairs of the American Medical Association asserted that it is not permissible. ${ }^{6}$ Consent must be obtained from family members; if getting their consent is impossible, the procedures cannot be performed.

\section{[B] Practising pelvic exams on anaesthetised women} Until relatively recently, it was commonplace for medical students to conduct practice pelvic examinations on women who were anaesthetised for gynaecological surgery, without the patients' consent. Under anaesthesia, women are relaxed and thus easier to examine than when they are conscious; additionally, they will not be troubled by novice examiners' unpractised handling. In the mid-1990s, several medical schools, including Harvard and the University of California, adopted policies requiring consent for these examinations. Coldicott et al suggest that this change in policy reflects an attitude shift toward Kantian Ethics. ${ }^{7}$

In contrast with these cases, we can note three relevant points about typical medical learning:

\section{(1) Medical learning exposes patients to risk}

In the two cases described above, the patients are exposed to little or no risk of physical harm. With regard to case [A], the dead are beyond harm. They cannot feel pain or distress, nor can their health decline as a result of the residents' actions. (That does not mean, of course, that anything goes with regard to how we treat the dead.) For case [B], the probability of a woman suffering harm from a pelvic exam is very low. Should she learn that she was used in this way, she might well experience distress. It is, however, the knowledge that the examination was carried out without her consent that causes the distress, not the examination itself.

In contrast, many procedures that medical learners perform can indeed cause significant harm to patients. In his memoir of his residency experiences, Atul Gawande describes a common situation: A patient needs a particular procedure done. There are experienced physicians available who could do the procedure with ease. Instead, a supervisor assigns the procedure to a novice so that he can learn how to do it (Gawande, ${ }^{1}$ pp 11, 34). Gawande focuses on the procedure of inserting a central line. This involves inserting a long needle into the patient's chest, into the vena cava (the main blood vessel to the heart), carefully avoiding hitting a lung or an artery. Afterwards, one must enlarge the opening in the blood vessel and use a guide wire to correctly place a catheter (the central line), which is then sutured to the patient's chest (Gawande, ${ }^{1}$ pp 12-13).

A central line can be inserted using only local anaesthesia. When an experienced surgeon performs the insertion, serious complications rarely arise. Gawande suggests, however, that errors made by new residents are more likely to lead to life threatening problems, such as massive bleeding or cardiac arrest. He supports this claim with anecdotal, rather than statistical, evidence (Gawande, ${ }^{1}$ p 12). At the very least, it is reasonable to suppose that having a novice perform this delicate procedure may increase the amount of poking and prodding involved, thus increasing the patient's discomfort and stress level.

While Gawande's anecdotal example is suggestive, a recent statistical study on surgeon volume (the frequency with which a surgeon performs a particular procedure) and operative mortality provides stronger evidence that medical learning exposes patients to risk. Using information from the United States national Medicare claims database for 1998 and 1999, Birkmeyer et al examined mortality among all 474108 patients who underwent one of eight cardiovascular procedures or cancer resections. ${ }^{8}$ They concluded that, for many procedures, "Patients can often improve their chances of survival substantially, even at high volume hospitals, by selecting surgeons who perform the operations frequently" (Birkmeyer et al, ${ }^{8} \mathrm{p}$ 2117). High volume surgeons are presumably higher up on the learning curve for performing these procedures than are low volume surgeons.

(2) Learning curves are ubiquitous, not limited to medical students and residents

Cases [A] and [B] involve people we typically think of as "learners" still in the process of developing medical expertise: medical students and residents. This may give the impression that the issue of medical learning involves only a small period of time at the beginning of each doctor's career.

This impression is false. Medicine is constantly advancing, requiring even seasoned doctors to acquire new skills throughout their tenure (Gawande, ${ }^{1}$ pp 25-28). As Gawande puts it: "New technologies and operations emerge to supplant the old, and the learning curve starts all over again" (Gawande, ${ }^{1}$ p 25). He offers the instructive example of his father, a urologist with over twenty five years of experience, who, postresidency, has had to learn: "to put in penis prostheses, to perform microsurgery, to reverse vasectomies, to do nerve-sparing prostatectomies, to implant artificial urinary sphincters. He has had to learn shockwave lithotripters, electrohydraulic lithotripters, and laser lithotripters (all instruments for breaking up kidney stones); to deploy double $\mathrm{J}$ ureteral stents and silicone figure four coil stents and retro-inject multilength stents (do not even ask); to manoeuvre fibreoptic ureteroscopes. All these technologies and techniques were introduced since he finished training. Some of the procedures built on previous skills. Many did not" (Gawande, ${ }^{1}$ pp 25-26).

Problematically, early attempts at using new techniques may yield worse results for patients than do older, established techniques. Bull et al-for example, demonstrate that transitioning to a new surgical procedure for treating children with arterial transposition resulted in improved survival rates in the long run; but, before improvement, came "a period of increased hazard" with higher mortality rates associated with the new procedure. ${ }^{9}$

Learning curves tend to be particularly steep in the case of pioneering techniques or procedures. Consider-for example, 
Hasan et al's discussion of the Ross procedure, first described by Donald Ross in 1967. ${ }^{10}$ Now considered an acceptable alternative to aortic valve replacement in adults with aortic valve abnormalities, this procedure involves replacing the patient's diseased aortic valve with his or her normal pulmonary valve, and then using a homograft to repair the resulting defect in the right ventricular outflow tract and main pulmonary artery (Hasan et al, ${ }^{10} \mathrm{p}$ 171). Complex and technically demanding, a steep learning curve appears to be associated with this operation: "In Donald Ross's own series, $23 \%$ of patients died during the first year of operation, and $18 \%$ in the second year. In the subsequent 10 years, the surgical mortality in 188 patients was $9 \%$. Even in patients operated on more recently, mortality is higher in early experience: Stelzer had three deaths in the first 15 patients but only four deaths in the subsequent 130 patients" (Hasan et al, ${ }^{10} \mathrm{p} \mathrm{172)}$.

(3) The problem is unlikely to be resolved through better consent procedures

With cases [A] and [B], we can avoid controversy by requiring informed consent from the patient or family before the procedures can be performed. In these cases, the procedures do not address the patient's medical needs. Thus, it seems clear that any consent the patient gives for his or her medical care would not cover such extra procedures. So, seeking separate consent is appropriate.

Furthermore, in these kinds of cases, requiring that consent be secured would not severely impede medical education. Preliminary research indicates that the majority of women would agree to let medical students perform practice pelvic examinations on them, if they were asked beforehand. ${ }^{11}$ Similarly, 59 to $75 \%$ of families consented to allow procedures on the newly deceased. ${ }^{12}$ Thus, even if some patients or families refuse to consent, there is reason to believe that there will be ample opportunities for medical learners to practise.

What if we required that patients be informed about the practitioner's experience level as part of the informed consent process for all procedures? It is hard to object to giving patients access to relevant information. For many relatively low risk procedures, a full disclosure and patient choice policy would probably be successful: patients would know what they were getting into, and enough of them would agree to accept less experienced practitioners to ensure that the next generation of doctors could be well trained in these procedures.

We cannot expect such an agreeable outcome, however, when it comes to riskier or potentially more unpleasant procedures. Ubel and Silver-Isenstadt found that $78 \%$ of patients would probably or definitely not allow a medical student to perform a spinal tap on them (Ubel et al, ${ }^{11} \mathrm{p} 233$ ). Gawande, a doctor in training himself, rejected an apparently quite competent cardiology fellow in favour of an experienced cardiologist for the care of his infant son (Gawande, ${ }^{1}$ pp 3132). When the stakes are high, it is reasonable for a patient to want a practitioner who is at the high end of his or her learning curve with respect to the relevant skills. Yet, if all patients were able to choose to have the most experienced physicians, that would preclude other physicians from becoming experienced. As Hasan et al point out in the case of surgery: "Patients, and in the case of children, their parents, increasingly want to know about an individual surgeon's results, and without some basis for confidence they are unlikely to want to be a "guinea pig" on the first occasion that a surgeon performs a procedure. Yet every surgeon has to perform a procedure for the first time" (Hasan et al, $\left.{ }^{10} \mathrm{p} 172\right)$.

\section{USING PATIENTS AS A MEANS ONLY}

Kant does not say it is necessarily wrong to treat another person as a means; what is wrong is treating somebody merely as a means or as a means only. For Kant, treating someone as an end involves respecting that person's rationality (ability to make reasoned decisions) and intrinsic worth. Treating people as a means is compatible with this, although treating people as a means only is not. When-for example, patients seek out treatment from medical practitioners, they are presumably treating the latter as a means toward maintaining or improving their health. The patients are not, however, by virtue of this fact alone, treating medical practitioners as a means only. As rational agents, medical practitioners have agreed to participate in the health care system. To the extent that patients are using them for medical treatment and consultation, medical practitioners are being used with their consent, and thus are being treated not just as means, but as ends as well.

Medical students, residents, and doctors who gain expertise through practising procedures on patients do seem to be treating those patients as a means-a means to become better physicians. The question is: "are the patients being used as a means only". In this connection, consider the following possible rationales for answering "no".

1. One such rationale is that, although interested in gaining expertise, medical personnel are also interested in helping their patients. A resident who inserts his first central line-for example, has two goals: (1) to learn how to do the procedure, but also (2) to give the patient what she needs-that is, a central line. Achieving the first goal involves treating the patient as a means, but achieving the second involves treating the patient as an end.

This line of reasoning presupposes that giving the patient what she needs, or benefits from, amounts to treating her as an end, a supposition we will later contest. Additionally, the rationale fails because, although the patient may well get what she needs, she is not treated as an end if she receives needed treatment in a way that unnecessarily exposes her to risk of harm. (Here, "unnecessarily" pertains to the patient's interests, not broader, societal interests.) Even if we suppose, for the sake of argument, that the resident who does the procedure is not treating his patient as a means only, the supervisor who assigns him the job (rather than doing it herself) is. She decides to let the novice do the procedure with the goal of helping the novice learn, and thus benefit his future patients. The supervisor, naturally, also wants the patient to get the medical care she needs. But, by not taking the most effective route to providing that care-namely, doing the procedure herself, or assigning it to somebody with experience-she is not treating the patient as an end. The supervisor in effect exposes the patient to risk of harm, not for the benefit of the patient, but for the benefit of the resident's future patients. Doing so does not mesh with the Kantian Ideal of treating this patient as an end, and not as a means only.

In this connection, an anonymous reviewer of this journal suggested that "supervisors might undertake to delegate only under conditions where they can be as sure as possible that the procedure would be done as well as they could do it themselves. If this assurance can truly be given by the supervising doctor, then the conflict is solved."

In response to this suggestion, a question naturally arises concerning how we are to understand "delegate" here. We may distinguish between two kinds of delegating: (i) the supervisor delegating a procedure to a novice while remaining present and observing the procedure, and (ii) the supervisor delegating a procedure to a novice and leaving to attend to other matters. With the supervisor better placed to 
intervene if necessary, delegating in sense (i) obviously seems more conducive to protecting the patient from harm than delegating in sense (ii), for having a novice perform a procedure without supervision would presumably expose the patient to higher risk of harm. Even with the supervisor present, however, the latter's hand is not on the needle or scalpel, so to speak. She can guide the novice and take steps to ameliorate damage if the novice does something wrong, but the fact that the novice is learning the procedure exposes the patient to higher risk of harm than if the supervisor did the procedure herself. In other words, given the reality of medical learning curves, even if delegating in sense (i) exposes the patient to lower risk of harm than delegating in sense (ii), it still exposes the patient to higher risk of harm than having the supervisor do the procedure herself.

Moreover, if supervisors followed the reviewer's suggestion, and delegated (whether in sense (i) or (ii)) "only under conditions where they can be as sure as possible that the procedure would be done as well as they could do it themselves", they would presumably not delegate many medical procedures (such as insertion of a central line, performing the Ross procedure, etc), the mastery of which requires (often considerable) practice on live, human patients. This is because, given the learning curves associated with the mastery of such procedures, supervisors could not be "as sure as possible that the procedure would be done as well as they could do it themselves". Hence, novices would be precluded from the very practice they need to acquire mastery of such procedures. We conclude therefore that the reviewer's suggestion does not resolve the conflict between the Kantian Ideal and the reality of medical learning curves.

2. Another rationale for thinking that gaining expertise through performing procedures on patients might be consistent with Kant's directive arises when we think of the "big picture" of medical care. Although, with respect to a particular procedure, a patient might be better off having an experienced doctor rather than a novice, it is in all of our best interests to have high quality medical care in the future. Thus, the patient is not treated merely as a means for developing expertise, but also as the potential future beneficiary of the cumulative expertise produced by the medical system-that is, as an end.

This line of reasoning also fails to show that patients are not being used as a means only. For, even on the assumption that doing what it is beneficial to a patient is tantamount to treating her as an end, it is false that all patients have a vested interest in the future of medicine. Patients with short life expectancies would not suffer, were the next generation of doctors ill prepared. They are not "potential future beneficiaries" of doctors' developing skills.

This rationale can, however, be revised as follows: although having a novice perform a procedure may increase the risk to the patient from that procedure, institutions that permit novices to perform some procedures-that is, "teaching hospitals"-have overall better patient outcomes than do non-teaching institutions (Gawande, ${ }^{1}$ p 24). So, in the big picture, whether or not a patient lives long enough to enjoy the fruits of her novice doctor's developing skills, she benefits from being a patient of an institution that develops such skills.

Unfortunately, it is not clear that showing that some practice benefits a patient is sufficient for showing that the patient is being treated as an end. Kant's idea that humans should be treated as ends, not as means only, is tied to his belief that humans are intrinsically valuable. He held that our value is grounded in the fact that humans, unlike dogs and rocks, are rational. We are able to choose goals for ourselves and make decisions in order to attain these goals. So, when
Kant tells us to "treat humanity in each person always as an end", he tells us not only to do what benefits each person, but also to respect the rationality of each person.

It is possible to do what benefits someone without thereby respecting that person's rationality. Quitting smoking-for example, would benefit smokers immensely; however, some smokers show no inclination to quit. Suppose we lied to a smoker, and thereby convinced him that, because of some genetic predisposition, if he did not stop smoking, he would be dead by the age of 50. Suppose that, based on this (probably) false information, the smoker quits. Though our action benefits him, it does so in a way that does not respect his rationality. By manipulating him, rather than appealing to his ability to reason, we are, in a sense, using him to help himself. And using someone, even if only to help himself, does not square with the Kantian ideal of never treating someone as a means only.

Gaining expertise by performing procedures on patients may be construed similarly. In the big picture, the practice benefits all of us, patients included. Given the risks involved, however, it is quite reasonable for a patient not to want to participate in the learning process. Not giving the patient the opportunity to make a fully informed choice on the matter seems equivalent to not respecting his or her rationality, and thus, to treating him or her as a means only.

3. Third, one might try to avoid the charge that patients are being treated as means only by combining the "big picture" considerations, discussed above, with one of Kant's own tenets. Kant offers the following version of the categorical imperative as the basic principle of morality: "Act only in accordance with that maxim through which you can at the same time will that it become a universal law" (Kant, ${ }^{2} \mathrm{p}$ 37). This means that one should only perform actions that it would be reasonable to want everybody to perform. This principle famously excludes lying, because, if everybody lied, communication would be impossible. Kant also intends the principle to apply to refraining from acting. Thus, he concludes that failing to help others in need and failing to develop one's own talents conflict with morality.

So, on Kantian grounds, it might be argued that it is all right to practise on patients, since following the categorical imperative requires them to agree to such practice. Suppose a patient contemplates whether it is morally permissible to refuse to allow a novice to perform a procedure on him. Applying the categorical imperative, he must ask himself what would happen if everybody refused, and determine whether it is reasonable to desire such an outcome. The outcome-no opportunities for doctors in training to practise that procedure, resulting in poorer future care-is undesirable. So, the patient ought to submit himself to the novice's care.

In some situations the outcome of the categorical imperative may be debatable. Suppose-for example, a critically ill patient is considering whether she ought to allow a novice to perform a procedure whose potential complications could be fatal for someone in her condition, though they would be merely unpleasant for a healthier person. What is the scope of the "universal law" she must evaluate? The patient might reasonably conclude that it would be undesirable for everybody to refuse to let novices perform the procedure, but that it would be acceptable for everybody in her condition to refuse, since doctors in training could get ample practice on healthier patients.

Even granting this sort of exception, we are left with the conclusion that Kant's imperative often morally requires patients to accept treatment from less experienced practitioners. Does this show that these patients are not being used 
as means only? No. The fact that a particular patient ought to volunteer to be practised upon does not imply that it is permissible for us to volunteer him without his consent. If a patient does, in fact, consent to be practised upon, then accepting his decision demonstrates respect for his rationality. Deciding for the patient shows no such respect. Thus, one is still using a patient as a means only, even if the patient ought to agree to such treatment.

4. A fourth rationale for avoiding the conclusion that gaining expertise through practice on patients amounts to treating them as means only hinges on the idea that patients can "opt out" of this role. That is, patients can seek treatment only from institutions that permit them to choose doctors who are experienced in the relevant procedures, or they can choose to avoid medical care altogether. If a patient stays on as a patient after being informed that some of his care may be provided by medical learners, he has thereby implicitly consented to take part in this system. Having rationally chosen to participate, he is not being used as a means only.

This rationale, also, is unconvincing. While some people have the funds or means of acquiring medical care from the practitioner of their choice, for those who do not, this is not a viable option. These people are left with the option of avoiding medical treatment altogether. Except for mandatory treatment of dependent children, avoiding medical care is, for the most part, possible, though it is likely to reduce, sometimes severely, one's quality of life and longevity. Given this bleak alternative, it is hard to see how these people's opting into the health care system can be construed as the kind of "rational choice" suggested by this rationale. For them, it is, at best, a coerced choice, one which does not negate the charge that they are being treated as a means only when medical personnel gain expertise by practising procedures on them.

What is more, in a scenario where everyone had the funds or means of acquiring medical care from the practitioner of their choice, there would still be the problem that, if too many people chose to receive medical care only from experienced medical personnel, novices would be unable to acquire the kinds of medical expertise that require practising on live, human patients, and even experienced personnel would be unable to master new procedures that require such practice.

\section{CONCLUSION}

The problem we have been concerned with in this paper may be summarised as a prima facie conflict between the following:

(1) The Kantian ideal: Medical practitioners should always treat patients as ends in themselves, and never only as a means to other ends.

(2) The reality of medical practice: At the present time at least, medical practitioners can only acquire certain skills and abilities by practising on live, human patients; and given the inevitability and ubiquity of learning curves, this learning requires some patients to be treated only as means to this end.

We have considered a number of ways of attempting to establish the compatibility of (1) and (2), and found each deficient. Accordingly, until a way is found to reconcile them, we conclude that the Kantian ideal is inconsistent with the reality of medical practice.

Where do we go from here? If two items are inconsistent with each other, one must reject, or substantially modify, one of them. We believe that the Kantian ideal, rather than medical practice, must give. With the current state of technology and the reality of learning curves, it is impossible for new doctors to gain expertise, or for experienced doctors to gain expertise in new areas, without using patients as means only-at least to some extent. The benefits of this expertise are too valuable to pass up.

Yet, the Kantian ideal remains important as an ideal-as a goal that may not be fully achieved. It protects individual patients from having their welfare sacrificed for the greater good. Although medical learning curves demand that we sometimes fall short of achieving this goal, we would like to conclude by mentioning four ways which may help to bring us closer to achieving it:

(1) Discontinuing unnecessary use of patients without consent

Allowing medical learners to perform pelvic examinations on anaesthetised women or perform procedures on the newly dead, without consent of the patient or family, had been deemed acceptable on the grounds that it was necessary for the educational process. Changing policies to require consent seems to have produced no dire consequences for medical education. We can come closer to the Kantian ideal by critically examining other practices and procedures to determine if their educational goals could be accomplished without using patients as means only.

\section{(2) Continuing to develop medical simulations}

The more prior practice one can acquire on appropriate models, the further along the learning curve one will be when one treats actual patients. Innovative simulations are already available for such procedures as placing an intravenous (IV) line ${ }^{13}$ and performing bronchoscopies and sigmoidoscopies. ${ }^{14}$ Improving current simulations and developing simulations for more procedures can substantially reduce the conflict between the Kantian Ideal and the need to provide adequate practice opportunities.

\section{(3) Enhancing support and supervision of medical learners}

All medical learners need practice, but individual institutions and medical cultures vary with respect to how much study and closely supervised practice is required before a novice is deemed fit to perform a particular procedure independently. The "see one, do one, teach one" model advocates a very rapid progression. As this model presupposes an unrealistically short learning curve, we would like to add our voices to the chorus of critics who oppose it. ${ }^{15}$ At the opposite extreme, suppose a supervisor refrained from permitting his trainee to perform a procedure until he was confident that the trainee could perform it as well as he could himself. This would avoid conflict with the Kantian ideal, since the patient would not be exposed to additional risks for the benefit of others. (Of course, the conflict still stands for new procedures for which there is no expert available.)

We are sceptical that such an approach, applied stringently, is practical for all procedures. It is hard to imagine-for example, that an experienced surgeon can honestly say that his trainee's first liver biopsy will be performed just as well as he would perform it himself. Moving in this direction, toward a more conservative educational model, would, however, reduce the extent to which patients are used as means only.

(4) Universalising, in the sense of treating all patients according to evidence based statistical outcomes

Finally, a valuable suggestion offered by an anonymous reviewer of this journal points to another way of approximating the Kantian ideal. The idea is to universalise "so that 
the patient is regarded as being, for moral purposes, an individual requiring procedure $\mathrm{x}$, and the patient therefore has a right to receive that procedure as performed for the average patient in that position in the light of the constraints that apply". As the reviewer puts it: "On this basis the procedure is reckoned to be an average procedure applied in the light of evidence based statistical outcomes (which include training cases). This would only debar the use of an untrained operator in conditions where adequate supervision-that is, the ability to intervene to avert adverse events was unavailable." Universalising using evidence based statistical outcomes may not be tantamount to fully achieving the Kantian ideal of treating each patient as an end in his or her own right, since doing so de-emphasies the importance of each unique individual. It does, however, offer a useful way of approximating this ideal in light of the constraints imposed by the reality of medical practice.

\section{ACKNOWLEDGEMENTS}

Thanks to the two anonymous reviewers of this journal for helpful comments and suggestions.

\section{Authors' affiliations}

P Le Morvan, Department of Philosophy and Religion, The College of New Jersey, Ewing, New Jersey USA

B Stock, Department of Philosophy and Religion, Gallaudet University, Washington, DC, USA

\section{REFERENCES}

1 Gawande A. Complications: a surgeon's notes on an imperfect science. New York: Metropolitan Books, 2002:19.

2 Kant I. Groundwork of the metaphysics of morals, In: Wood AR, ed. New Haven, CT: Yale University Press, 2002:46-7.

3 Aristotle. Nicomachean ethics. In: Ackrill JL, ed. A new Aristotle reader [trans Ross WD]. Princeton NJ: Princeton University Press, 1987:1181b.

4 Wright TP. Factors affecting the cost of airplanes. Journal of the Aeronautical Sciences 1936;3:122-8.

5 Iserson K. Case: Practising procedures on the newly dead in ethics. In: Iserson KV, Sanders AB, Mathieu D, et al, eds. Ethics in emergency medicine. Tucson, AZ: Galen Press, 1995. www.galenpress.com/extras/extra20htm (accessed 25 Nov 2004).

6 Lagay F. Consent needed to perform procedures on the newly deceased for training purposes. Virtual Mentor: ethics journal of the American Medical Association 2001 (online journal). www.amaassn.org/ama/pub/category/ 5721.html (accessed 25 Nov 2004).

7 Coldicott Y, Pope C, Roberts C, et al. The ethics of intimate examinationsteaching tomorrow's doctors. BMJ 2003;326:97-101.

8 Birkmeyer J, Stukel T, Siewers A, et al. Surgeon volume and operative mortality in the United States. N Engl J Med 2003:349:21 17-27.

9 Bull C, Yates R, Sarkar D, et al. Scientific, ethical and logistical considerations in introducing a new operation: a retrospective cohort study from paediatric surgery. BMJ 2000;320:1168-73.

10 Hasan A, Pozzi M, Hamilton J, et al. New surgical procedures: can we minimise the learning curve? BMJ 2000;320:171-3.

11 Ubel P, Silver-Isenstadt A. Are patients willing to participate in medical education? J Clin Ethics 2000;11:230-5.

12 McNamara RM, Monti S, Kelly JJ, et al. Requesting consent for an invasive procedure in deceased adults. JAMA 1995:273:310-12.

$13 \mathrm{http}: / / \mathrm{hmc}$.psu.edu/simulation/Equipment/CathSim_IV_Trainer/ cathsim_iv_trainer.html (accessed 25 Nov 2004).

$14 \mathrm{http}: / / \mathrm{www} . \mathrm{hmc}$.psu.edu/simulation/Equipment/Endoscopy_Trainer/ endoscopy_trainer.html (accessed 25 Nov 2004).

15 Supanich B. Asking for help: who's listening? (commentary). In: Kushner TK, Thomasma DC, eds. Ward ethics. Cambridge: Cambridge University Press, 2001:70

\section{1th European Forum on Quality Improvement in Health Care}

26-28 April 2006, Prague, Czech Republic

For further information please go to: www.quality.bmipg.com

Book early to benefit from a discounted delegate rate 